\title{
Shear behavior of concrete beams reinforced exclusively with longitudinal GFRP bars: experimental research
}

Monika Kaszubska, Renata Kotynia, Joaquim A.O. Barros, Hadi Baghi

\begin{abstract}
This paper aims to investigate the shear failure mechanisms in beams exclusively reinforced with longitudinal glass fiber reinforced polymer (GFRP) bars, and to propose a design based approach to predict the shear capacity of this type of beams. An experimental program composed of seven T cross section shape concrete beams was executed to analyze the influence of the flexural reinforcement configuration on the shear capacity and deformability of the beams. Three values of the flexural reinforcement ratio $\left(\rho_{l}\right), 1 \%$, $1.4 \%$ and $1.80 \%$ were adopted. Digital image correlation (DIC) technique was used to better capture and analyze the cracking process up to the formation of the shear failure crack. Test results indicated that the shear capacity was not dependent of $\rho_{l}$ up to a limit of around $1.4 \%$, but a tendency of the shear capacity to increase with $\rho_{l}$ was registered above this limit due to a more pronounced favorable contribution of aggregate interlock and dowel effect.
\end{abstract}

Keynotes: T-shape RC beams, GFRP flexural reinforcement, shear failure, shear capacity, aggregate interlock, dowel effect, DIC 


\section{INTRODUCTION}

Generally, the shear resistance of reinforced concrete (RC) beams or slabs is determined as a sum of the shear resistance attributed to the concrete $V_{R d, c}$ and the shear resistance provided by the shear reinforcement $V_{R d, s .}$ According to Eurocode 2, [1] in regions of a member where $V_{E d} \leqslant V_{R d, c}$ no calculated shear reinforcement is necessary, where $V_{E d}$ is the design shear force in the considered section, resulting from external loadings and prestressing force. In regions where $V_{E d}>V_{R d, c}$, sufficient shear reinforcement should be provided in order to satisfy the condition $V_{E d} \leqslant V_{R d}=V_{R d, s}$, which means that the concrete contribution for the shear resistance of the member is not considered.

Many structures constructed in 1960s have RC slabs without shear reinforcement. Since significant part of these slabs are still being used without any damage, a reasonable question that can be erased is about the reliability of actual existing codes on the prediction of the shear capacity of RC members without transverse reinforcement.

On the other hand, intense research was carried out on RC members without shear reinforcement, by investigating the influence of several parameters on the shear capacity of this type of members (e.g. size effect, concrete strength, shear span to depth ratio, flexural reinforcement ratio etc.) $[2,3,4,5]$. Despite the strong research effort on the shear transfer mechanisms in RC beams without stirrups $[2,3]$, this issue still raises many doubts and controversial opinions, due to the difficulties of isolating each mechanism and capture it's influence on the shear capacity of a RC member, as well as the large scatter of results, even in members of same concrete strength and longitudinal reinforcement ratio.

The shear capacity of RC beams without stirrups is governed by the following main shear transfer mechanisms: aggregate interlock effect $\left(V_{a}\right)$ [2], dowel action of the longitudinal (flexural) reinforcement $\left(V_{d}\right)[6]$, the uncracked concrete in the compressive zone $\left(V_{c}\right)$ [7], and the direct strut action for point loads close to the support [3].

More frequent use of fiber reinforced polymers (FRP) bars for the flexural reinforcement of concrete elements due to their corrosion immunity, high strength-to-weight ratio, good fatigue behavior and nonmagnetic nature $[8,9]$ and smaller elasticity modulus than of steel bars, which together the smaller bond performance [10], place extra challenges in terms of accomplishing the performance requisites for serviceability limit state conditions, mainly in the crack width and deflection. The modulus of elasticity of FRP reinforcement varies between $32 \mathrm{GPa}$ to $148 \mathrm{GPa}$, depending on the type of fibers: GFRP $-32 \div 52 \mathrm{GPa}$, carbon fiber reinforced polymer $105 \div 148$ GPa (CFRP), aramid fiber reinforced polymer (AFRP) $-47 \div 81$ $\mathrm{GPa})$.

In the context of the shear capacity of RC elements, the use of FRP bars of these requisites can have detrimental implications in terms of dowel effect and aggregate interlock, since their smaller axial and shear stiffness allows the occurrence of larger opening and sliding of the critical diagonal cracks. 
In fact, the experimental tests carried out with concrete beams flexurally reinforced with FRP bars and without transverse reinforcement [11] indicated that when using this type of reinforcement instead of steel bars, the shear strength of the beams is smaller. Comparing the beams with the same longitudinal reinforcement ratio, it was indicated that the difference in the shear strength ranged between $30 \%$ and $50 \%$ for GFRP; between 10\% and 40\% for AFRP; and between 5\% and 19\% for CFRP bars [12, 13]. This decrease on the shear capacity was caused by the lower modulus of elasticity of FRP bars, as well as their smaller bond attributes, which have promoted the occurrence of larger crack widths, with detrimental consequences on the favorable mechanisms of the aggregate interlock and dowel effect $[14,15,16]$. It was also observed that the differences in the shear strength between FRP and steel reinforced members have decreased with the increase of the flexural reinforcement ratio.

The most existing research investigated the effect of the longitudinal FRP reinforcement ratio $\left(\rho_{l}\right)$ and its stiffness on the shear strength. While Yost et al. [4] indicated that the GFRP longitudinal reinforcement ratio did not affect the shear capacity, Alkhrdaji et al. [17], El-Sayed et al. [18, 20], Matta et al. [19], Tureyen and Frosch [12], and Razaquur et al. [5] demonstrated that the shear strength of the GFRP and CFRP reinforced beams was proportional to the $\rho_{l}$. Based on the tests collected in the data base (DB) of concrete beams reinforced exclusively with FRP bars [11], the influence on the failure mechanisms and beam's shear capacity of the following parameters was investigated: concrete compressive strength, shear span to depth ratio, $\rho_{l}$, and axial stiffness of the longitudinal reinforcement. The increase in the axial stiffness of the flexural reinforcement $\left(\rho_{l} E_{l}\right)$ makes the increase in the shear strength. Moreover, the increase in the compressive concrete strength causes the increase in the normalized shear stress $\left(V_{\max } /\left(\sqrt{f_{c}} b_{w} d_{e q}\right)\right)[11]$. To understand the shear behavior of FRP reinforced beams without transverse reinforcement, deeper analysis of the crack development during the process of shear failure is important. Moreover, to obtain better interpretation of the test results and to explain the complex shear failure mechanisms digital measurements based on photogrammetry tools should be involved to enable detailed investigation of the shear failure process.

The existing codes based on the truss mechanism assume that shear is taken by the web only, and do not consider any contribution of the flange to the shear strength. Hence, most of published experimental research on concrete beams flexurally reinforced with FRP bars and without shear reinforcement adopts only rectangular cross sections, despite real beams are monolithically joined to the slabs, which provides to the beam a $\mathrm{T}$ cross section shape. Furthermore, it is recognized the favorable influence of the contribution of the flange (located in the compressive zone of the section) for the shear capacity of RC beams [21, 22, 23, $\mathrm{X}]$. Based on these considerations, in the present experimental program $\mathrm{RC}$ beams of $\mathrm{T}$ cross section were adopted. 


\section{EXPERIMENTAL PROGRAM}

The main aim of the experimental research on concrete beams exclusively reinforced with GFRP bars (do not having any shear reinforcement) is to investigate the influence of the relevant characteristics of the flexural reinforcement (ratio, number of bars per layer, number of layers and bar diameter) on the shear behavior of this type of beams. In an attempt of providing detailed and deep analysis of the cracking process, and therefore, better understand the shear-transfer mechanisms in beams failing in shear, a digital image correlation (DIC) technique was used.

In order to promote the occurrence of diagonal-tension or shear-tension failure modes [24], in the experimental test program the ratio between shear span (a) and the internal arm of the flexural reinforcement $\left(d_{e q}\right)$ was between 2.9 and $3.0[27,28]$ The concept of equivalent internal arm of the flexural reinforcement $\left(d_{e q}\right)$ is used in this work in order to attend the beams where two layers of GFRP bars were applied.

The group of RC beams analyzed in this paper is part of an extensive experimental research program where other variables like the material type of the flexural reinforcement (steel or GFRP), concrete cover thickness of the flexural reinforcement ( $15 \mathrm{~mm}$ and $35 \mathrm{~mm}$ ), and the concrete strength class, are being investigated.

The experimental program treated in this paper is composed of seven T-section RC beams $\left(b_{\text {eff }}=400 \mathrm{~mm}\right.$, $b_{w}=150 \mathrm{~mm}, h_{f}=60 \mathrm{~mm}, h_{t o t}=400 \mathrm{~mm}$ ), single span and simply supported with a clear span of $1800 \mathrm{~mm}$, tested in three-point monotonic loading at the Laboratory of Concrete Structures in Lodz University of Technology (Figure 1). The beams did not include any shear reinforcement, and were flexurally reinforced with GFRP bars. To investigate the influence of the flexural reinforcement ratio $\left(\rho_{l}\right)$, number of bars per layer, number of layers and bar diameter on the beam's shear capacity, the flexural arrangements introduced in Table 1 were adopted. Therefore, values of $\rho_{l} \approx 1.0 \%, \approx 1.4 \%$ and $\approx 1.8 \%$ were considered, with the corresponding bar's diameters of $12 \mathrm{~mm}, 16 \mathrm{~mm}$ and $18 \mathrm{~mm}$. In all the beams a concrete cover thickness of $15 \mathrm{~mm}$ for the flexural reinforcement was assumed for maximizing the internal arm of this reinforcement taking the advantage of being not susceptible to corrosion. Mazaheripour et al. [10] demonstrated that below this cover thickness limit, debond can be negatively affected by the formation of splitting cracks in the alignment of the longitudinal bars.

For the designation of the beams of the present experimental program the following acronym was adopted, $\mathrm{G}-\mathrm{X} \phi-\mathrm{Y}-\mathrm{Z}$, where $\mathrm{G}$ means the flexural bars are of GFRP type, $\mathrm{X}$ is the number of bars of $\phi$ diameter (in $\mathrm{mm}$ ), Y represents the target average compressive strength for the concrete (in this series it is considered constant and equal about to $30 \mathrm{MPa}$ ), and $\mathrm{Z}$ is the cover thickness, that in the present program, as already indicated, is constant and equal to $15 \mathrm{~mm}$. For instance, G-512-30-15 is a beam flexurally reinforced with a layer of 5 bars of $12 \mathrm{~mm}$ diameter, of average concrete compressive strength of $30 \mathrm{MPa}$ and with a concrete cover thickness of $15 \mathrm{~mm}$. In the beams with two layers of flexural reinforcement, the beam's identification is $\mathrm{G}-\mathrm{X}_{1} \phi_{1} / \mathrm{X}_{2} \phi_{2}-\mathrm{Y}-\mathrm{Z}$, where $\mathrm{X}_{\mathrm{i}}$ and $\phi_{\mathrm{i}}$ represents the number and diameter of the $\mathrm{i}^{\text {th }}$ layer ( 1 or 2$)$. 
Since the bottom GFRP bars were straight, and taking into account the relative small length of the beam between its extremities and the closest support, the proper anchored conditions were ensured by embedding the bars into a steel box filled with an epoxy resin (Figure 1). The top longitudinal reinforcement of all the beams consisted of two straight GFRP bars of $10 \mathrm{~mm}$ diameter, maintained in their aimed position by using transversal short steel bars of $6 \mathrm{~mm}$ diameter at $210 \mathrm{~mm}$ spacing, located in the flange.

There were no stirrups in the largest shear span, while the shortest one was shear reinforced (closed steel stirrups of $8 \mathrm{~mm}$ diameter at $130 / 150 \mathrm{~mm}$ spacing, and steel bent bars of $14 \mathrm{~mm}$ diameter) in order to force the occurrence of shear failure in the largest span, where conventional monitoring (displacement transducers) and advanced techniques (DIC) were applied to recording the deformations and cracking process.

\section{TEST SETUP AND MONITORING SYSTEM}

The beams were simply supported on two steel supports with the movable (rotation and beam's axial displacement free movements) one in the monitored shear span, and the other with only free rotation movement (Figure 2). The load was applied under displacement control at $10 \mu \mathrm{m} / \mathrm{s}$ by using $\mathrm{T}$ cross section steel profile to distribute the applied load along the width of the flange (contacted area $10 \mathrm{~mm} \times 400 \mathrm{~mm}$ ). Concrete axial strains were evaluated by using displacement transducers (LVDTs) disposed in the middle depth of one of the lateral faces of the beam's flange (number 1 to 4), and LVDTs positioned $30 \mathrm{~mm}$ above the bottom beam's surface (number 5 to 8 ). For estimating the shear deformation in the tested shear span, three sets of LVDTs were disposed in a triangle configuration (delta rosettes) with a LVDT per each edge of the triangle (number 9 to 21). Vertical displacements were registered by eight LVDTs of $20 \mathrm{~mm}$ stroke and $0.1 \mathrm{~mm}$ accuracy (number 22 to 29) mounted on an independent steel frame (Figure 2).

The digital image correlation system was used to provide complementary information to the displacement measurements from LVDTs, and to help on the interpretation of the cracking process of the tested beams. The information from DIC is obtained by comparing digital photographs of a component or test piece at different stages of deformation. By tracking blocks of pixels, the system can measure surface displacement and build up the full 2D and 3D deformation vector fields and maps of concrete strain. The photogrammetric technique used in this research was prepared for 3D measurements using two cameras with a focal length of $50 \mathrm{~mm}$ and a resolution of 4 megapixels. The registered area of concrete was $500 \mathrm{~mm}$ wide and $340 \mathrm{~mm}$ high (depth of the web of the beam's cross section) located in the mid-span of the shear region (indicated by a square at dashed line in Figure 3). Pictures were taken at $1 \mathrm{~Hz}$ frequency, while images were analyzed using the VIC3D software [29].

Properties of the materials 


\section{Concrete}

The beams were made of concrete strength class C25/30, including sand (0-2 mm), crushed stone aggregate (2-8 mm), cement CEM I 42.5, plasticizer. The concrete mix was delivered from a local concrete plant. The concrete composition shown in Table 2 presents the S3 consistency class (according to EN 206-1 [30], slump cone in the range of 100 to $150 \mathrm{~mm})$, with a water/cement $(\mathrm{w} / \mathrm{c})$ ratio of 0.8 , which is relatively high due to the relatively low content of cement in order to achieve a characteristic concrete compressive strength of about $30 \mathrm{MPa}$ on cubic specimens (about $25 \mathrm{MPa}$ on cylinder specimens).

The strength properties of concrete were determined according to EN 206-1 standard [30]. The average cylinder concrete compressive strength (obtained on 16 specimens) was $31.7 \mathrm{MPa}(\mathrm{COV}=8 \%$ ), the average modulus of elasticity was $26.7 \mathrm{GPa}(\mathrm{COV}=6 \%)$, while the average splitting tensile strength (from Brazilian type test) was $2.9 \mathrm{MPa}(\mathrm{COV}=8 \%)$, indicating the concrete pertains to $\mathrm{C} 25 / 30$ strength class.

\section{GFRP bars}

The relevant tensile properties of the adopted GFRP reinforcement were determined from experimental tests carried out with 15 specimens according to ISO Standard 10406-1 [31]. The average modulus of elasticity and the tensile strength registered in the tests were $50.5 \mathrm{GPa}(\mathrm{COV}=1.6 \%)$ and $1091 \mathrm{MPa}(\mathrm{COV}=10.7 \%)$, respectively, Table 3.

\section{TEST RESULTS AND DISCUSSION}

\section{Crack patterns and load carrying capacity}

The analysis of the critical shear crack development in the tested beams was performed by using the images obtained from the photogrammetric technique at high frequencies. The description methodology of the cracking pattern and kinematics adopted in $[32,33]$ were adopted for the interpretation of the shear stress mechanisms developed until failure of the tested beams.

Primary cracks of flexural nature (type A), appeared close to the loaded section (in the highest bending moment region). By increasing the applied load, secondary cracks (type B) formed between the previous ones, in the zone close to the flexural reinforcement, in consequence of the bond stress transfer between this reinforcement and surrounding concrete. The type $\mathrm{C}$ cracks propagated towards the flexural cracks, and, when connected, formed the critical shear cracks. The degeneration of one of these critical shear cracks in a shear failure crack was governed by two different mechanisms in the extremities of this crack: in the top extremity the crack progressed to the applied load point due to the relatively high influence of both shear and bending moments in this zone; in the bottom extremity, the shear failure crack progressed along the interface between flexural reinforcement and surrounding concrete (cracks of type D) [33, 34]. The openingsliding mixed mode of the cracks type D is mainly governed by the sliding of the faces of the shear failure 
crack.. Cracks type E developed at both sides of the flexural primary or secondary crack (type A and B, respectively), and are consequence of the aggregate interlock resisting mechanism. When the primary flexural crack, attained the compression chord, its inclination became almost flat (type F), progressing preferentially at the web-flange interface of the T cross section. Finally, this $\mathrm{F}$ type crack degenerated in a $\mathrm{G}$ type crack that propagated to the loading zone with a higher inclination, crossing the flange. The $\mathrm{G}$ type crack formed in the flange of the beam due to the tensile stresses installed in this zone in consequence of the relative sliding between the two blocks separated by the shear failure crack. Due to the shear sliding between the two blocks the shear failure crack divides the beam, and the shear resistance offered by the reinforcement in the flange, a negative bending moment is introduced in the part of the flange between the zone of the $\mathrm{G}$ type crack and the zone corresponding to the interception of the shear failure crack and the flange. This negative bending moment installed in this segment of the flange, which is working like a cantilever, induces the occurrence of the cracks type $\mathrm{H}$.

For determining the inclination of the shear failure crack it is adopted the criterion schematically represented in Figure 3: line connecting the two points of the intersection of this crack with the middle depth of the beam's cross section and the flexural reinforcement. Assuming valid this criterion, it is verified that the inclination of the shear failure crack has the tendency of increasing with the flexural reinforcement ratio (from an average value of $30^{\circ}$ for $\rho_{l} \cong 1 \%, 43^{\circ}$ for $\rho_{l} \cong 1.4 \%$ and $51^{\circ}$ for $\rho_{l} \cong 1.8 \%$ ), (Table 4 ). By increasing $\rho_{l}$, the flexural capacity and stiffness of the beam in the cracking stage increases (Figure 4) due to the decrease of the maximum crack opening that promotes the favorable effect of the concrete aggregate interlock, as well as due to the dowel effect of the flexural reinforcement. This led to an increase of the beam's load carrying capacity (shear strength, $V_{\max }$ ) with $\rho_{l}$ (Table 4). Disposing the flexural reinforcement in two layers, these favorable effects are more pronounced, mainly when adopted the maximum $\rho_{l}$ (G318/118-30-15). Despite the inclination of the shear failure crack of this beam been similar to the inclination of the beam of similar $\rho_{l}$ but composed of only one layer of reinforcement (G-418-30-15), the maximum load of G-318/118- 30-15 beam was about 28\% higher than the one of G-418-30-15 (Figure 4).

Since the adopted flexural reinforcement configurations have different total bond perimeter of contact with the surrounding concrete, the influence of this parameter on the load carrying capacity was analyzed. The obtained results reveal a small tendency for the increase of the maximum shear force $V_{\max }$ (where $V_{\max }=$ $7 / 18 F_{\max }$ and $F_{\max }$ is the maximum load) with the contact perimeter of the flexural reinforcement of the beams with only one layer of reinforcement, while a significant increase in $V_{\max }$ was observed in the beams with two layers (see Table 1). The number of results is not, however, enough to derive reliable conclusion in this respect, so further research should be performed. 


\section{Deflection performance}

Figure 4 shows the relationship between the average of the vertical displacements registered by LVDTs number 24 and 25 (Figure 2) and the applied average shear stress $(\tau)$. These LVDTs are located on both sides of the steel profile used to distribute the applied load (see the detail included in Figure 2 for this purpose). The concept of average shear stress $\left(\tau=V /\left(b_{w} d_{e q}\right)\right.$, where $V$ is the shear force in the monitored span and $b_{w}$ is the width of the beam's web) was adopted in order to take into account the different flexural reinforcement depth on the shear capacity of the beam, by using the concept of equivalent internal arm, $d_{e q}=\left(A_{1} \times d_{1}+\right.$ $\left.A_{2} \times d_{2}\right) / A$, where $d_{i}$ and $A_{i}(i=1,2)$ are the depth and the cross sectional area, respectively, of the $i^{\text {th }}$ layer of reinforcement, and $A$ is the cross sectional area of the total reinforcement.

All the beams presented a similar linear behavior before cracking, but after cracking the stiffness increased with $\rho_{l}$, leading to a decrease of the deflection at maximum load with the increase of $\rho_{l}$ (more brittle behavior). While for the beams with the smallest $\rho_{l}$, no clear tendency was verified in terms of the maximum deformability of the beam when using one or two layers of flexural reinforcement (it should be noted that the difference on the internal arm in these two situations was, however, only $3 \%$ ), in the beams with the highest $\rho_{l}$, the deflection at peak load was maximum in the beam with two layers of flexural reinforcement (G-318/118-30-15). Analyzing Figure 3 it is verified that this beam presented more flexural cracks than G418-30-15 beam (of similar $\rho_{l}$, but with only one reinforcement layer) and larger fracture surface for the shear failure crack. From the obtained results no clear tendency is observed on the influence of the total perimeter of the flexural reinforcement on the deflection performance of the tested beams.

\section{Shear strength and strain}

Table 4 includes the maximum shear capacity of the tested beams, $\left.\tau_{\max }=V_{\max } /\left(b_{w} d_{e q}\right)\right)$, where $V_{\max }$ is the maximum shear force applied in the monitored span.

The average strains $\varepsilon_{a}, \varepsilon_{b}, \varepsilon_{c}$ obtained from the displacements recorded by the LVDTs (by dividing the measured displacement the base-reference length of $200 \mathrm{~mm}$, Figure 2) disposed in a triangular configuration (delta rosette), were used for the calculation of the principal strains $\varepsilon_{1}$ and $\varepsilon_{2}$ according to the following equation [35]:

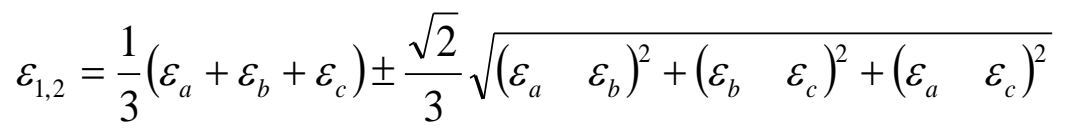

Only the rosette crossed by the shear failure crack was taken into consideration on the evaluation of the principal strains $\varepsilon_{1}$ and $\varepsilon_{2}$ in the concrete volume representative of this rosette. 
For evaluating the shear force corresponding to the initiation of the shear crack $\left(V_{c r}\right)$, the following criterion was followed: by scanning the principal strains in the rosettes, it was evaluated the load when the principal tensile strain, determined from Eq. (2), attained the concrete cracking strain, $\varepsilon_{c r}=f_{c t m} / E_{c}$, where $f_{c t m}$ is the average tensile strength (obtained according to Model Code 2010 [36], $f_{c t m}=0.3 \times\left(f_{c m}\right)^{2 / 3}$ ), and $E_{c}$ is the concrete Young's modulus. The cracking shear stress $\tau_{c r}=V_{c r} / b_{w} d_{e q}$, was calculated based on the shear cracking force $V_{c r}$.

The relationship between the average shear stress, $\tau$, and the principal strains, $\varepsilon_{1,2}$, is represented in Figure 5. This relationship was not obtained for G-418-30-15 and G-318-30-15 beams because the shear failure crack did not cross any of the three rosettes. The strain values indicated do not reflect realistically the concept of strain, since the major deformability recorded by the LVDTs is caused by the crack opening/sliding of the cracks crossing the measuring length of the LVDTs. In reality, with the opening and sliding progress of a shear crack, the surrounding concrete enters in an unloading process, mainly in the post-peak stage of the beam's test, and the strain level in this intact concrete has a tendency to decrease. Therefore, the strain values indicated in Figure 5, mainly in the post-peak stage, represent, fundamentally, the movements (opening and sliding) of the faces of the shear cracks crossing the corresponding rosette.

The results show that the average cracking shear stress, $\tau_{c r}$, increased with the flexural reinforcement ratio (Figures 5 and 6). The benefits, in terms of beam's shear capacity, of using two layers of flexural reinforcement instead of one layer for beams of equal flexural reinforcement ratio are visible when comparing the results of G-512-30-15 and G-312/212-30-15 beams. The shear capacity of the last one is much higher, mainly during the cracking propagation stage.

The obtained results indicate that the cracking shear stress, $\tau_{c r}$, varied between $0.12 f_{c t m}$ for beam G-512-3015 to $0.20 f_{c t m}$ for beam G-318/118-30-15, which correspond to $0.59 \tau_{\max }$ to $0.87 \tau_{\max }$ (Figure 6). The maximum shear stress $\tau_{\max }$ increased with the flexural reinforcement ratio (Figure 6). While for $\rho_{l} \cong 1.0 \%$, the $\tau_{\max }$ ranged between 0.56 to $0.63 \mathrm{MPa}$ (irrespectively of the number of the reinforcement layers), for $\rho_{l} \cong 1.4 \%$, the $\tau_{\max }$ attained values between 0.61 to $0.68 \mathrm{MPa}$. For the beams with the highest reinforcement ratio, $\rho_{l}$ $\cong 1.8 \%$, a significant difference in the $\tau_{\max }$ was registered for the beams with the flexural reinforcement located in one and two layers, respectively, $0.68 \mathrm{MPa}$ and $0.87 \mathrm{MPa}$. The slightly higher reinforcement ratio in the beam G-318/118-30-15 $\left(\rho_{l}=1.85 \%\right)$, together with the higher concrete strength may justify this difference.

Doubling the flexural reinforcement ratio (from $0.99 \%$ to $1.8 \%$ ) caused an increase in the beam's shear capacity of $11 \%$ when the flexural reinforcement was formed of one layer, while an increase of $25 \%$ was registered in the beams reinforced with two layers. When the flexural reinforcement is relatively high, the concentration of all the reinforcement in only one layer promotes a premature propagation of the shear 
failure crack along the top surface of the flexural reinforcement due to the abrupt transition of stiffness in this zone (Figure 3). Furthermore, distributing the flexural reinforcement has another beneficial effect, mainly when using relatively large reinforcement ratio, such it is the case of G-418-30-15 and G-318/118$30-15$ beams ( 1.8 and $1.85 \%$, respectively), since the profile of the critical shear cracks is more favorable to activate more effectively the aggregate interlock (triangular type configuration). In fact, having a relatively high flexural reinforcement in only one layer, the critical shear cracks tend to open more widely in the middle zone of the beam's web than in their extremities, which has a detrimental effect in the aggregate interlock shear mechanism. Finally, distributing the flexural reinforcement in more than one layer mobilizes a large volume of concrete under the influence of the tension stiffening effect, which improves the dowel effect shear mechanism.

\section{CONCLUSIONS}

The current work has assessed the influence of the flexural GFRP reinforcement on the shear strength of concrete beams without transverse reinforcement. From the experimental tests the following conclusions can be drawn:

- the inclination of the shear failure crack has the tendency of increasing with the flexural reinforcement ratio (average value of $30^{\circ}$ for $\rho_{l} \cong 1 \%, 43^{\circ}$ for $\rho_{l} \cong 1.4 \%$ and $51^{\circ}$ for $\rho_{l} \cong 1.8 \%$ );

- by increasing the flexural reinforcement ratio, the beam's loading carrying capacity and the stiffness have increased due to the decrease of the maximum crack opening, which has mobilized more effectively the favorable effects of the concrete aggregate interlock and dowel shear stress mechanisms;

- by arranging the flexural reinforcement in two layers, these favorable effects have become more pronounced, mainly when adopted the maximum reinforcement ratio $\left(\rho_{l}=1.85 \%\right)$, having been registered an increase of $28 \%$ in the shear strength when compared to the beam with the same reinforcement ratio, but placed in one layer;

- doubling the $\rho_{l}$ from $0.99 \%$ to $1.8 \%$ ) caused an increase in the beam's shear capacity of $11 \%$ when the flexural reinforcement was disposed in one layer, while the increase was $25 \%$ when arranged in two layers; the beams presented a similar linear behavior before cracking, but after cracking the stiffness increased with $\rho_{l}$, leading to a decrease in the deflection at the maximum load;

- when the flexural reinforcement is relatively high, the concentration of all the reinforcement in only one layer promotes a premature propagation of the shear failure crack along the top surface of the flexural reinforcement due to the abrupt transition of stiffness in this zone; 
- using relatively large flexural reinforcement $\left(\rho_{l} \cong 1.8 \%\right)$ in only one layer, the critical shear cracks tend to open more widely in the middle zone of the beam's web than in their extremities, which promotes a detrimental effect in the aggregate interlock shear mechanism;

- the digital image correlation system, based on photogrammetric techniques at high frequencies, is a very useful tool in the interpretation of the cracking process up to the failure of the beams;

\section{ACKNOWLEDGEMENTS}

The authors gratefully acknowledge the ComRebars Company who supplied the GFRP reinforcement for the experimental tests. The third author wish to acknowledge the grant SFRH/BSAB/114302/2016 provided by FCT. The support of the FCT through the project PTDC/ECM-EST/1882/2014 is also acknowledged

\section{REFERENCES}

[1] EN 1992, Eurocode 2: Design of Concrete Structures. Part 1-1: General Rules and Rules for Buildings, Brussels, 2004. 225 p.

[2] Walraven J.C., Fundamental analysis of aggregate interlock, ASCEE Journal of the Structural Division, 1981, 107 (11): pp 2245-2270.

[3] Kani G. N. J., The Riddle of Shear Failure and Its Solution, ACI Journal, 1964

[4] Yost J.R., Gross S.P., Dinehart D.W. and Associate Members.ASCE, Shear Strength Of Normal Strength Concrete Beams Reinforced With Deformed GFRP Bars, Journal of Composites for Construction, 2001, 5(4): pp.268-275

[5] Razaqpur A.G., Isgor B.O., Greenaway S., Selley A.: Concrete contribution to the shear resistance of fiber reinforced polymer reinforced concrete members, Journal of Composites for Construction, 2004, 8(5): pp. $452-460$

[6] Pruijssers, A.F., Aggregate Interlock and Dowel Action under Monotonic and Cyclic Loading, Doctoral Thesis, Delft University of Technology, Delft, the Netherlands, 1988, 165 pp.

[7] Fenwick, R.C. and Paulay T. (1968), Mechanisms of shear resistance of concrete beams, ASCE J. Structural Engineering, 1968, 94 (10): pp. 2325-2350

[8] Mazaheripour, H.; Barros, J.A.O.; Soltanzadeh, F.; Sena-Cruz, J.M., "Deflection and cracking behavior of SFRSCC beams reinforced with hybrid prestressed GFRP and steel reinforcements", Engineering Structures Journal, 2016, 125: pp.546-565

[9] Soltanzadeh, F.; Behbahani, A.E.; Barros, J.A.O.; Mazaheripour, H., "Effect of fiber dosage and prestress level on shear behavior of hybrid GFRP-steel reinforced concrete I shape beams without stirrups", Composites Part B Journal, 2016, 102: pp. 57-77 
[10] Mazaheripour, H.; Barros, J.A.O.; Sena-Cruz, J.M.; Pepe, M; Martinelli, E., Experimental study on bond performance of GFRP bars in self-compacting steel fiber reinforced concrete, Composite Structures Journal, 2013, 95: pp. 202-212

[11] Kotynia R, Kaszubska M: Analysis of Concrete Contribution in the Shear Strength of Beams Reinforced With FRP / Steel Bars Without Stirrups, "fib Symposium 2016 proceedings", Performance-Based Approaches for Concrete Structures, University of Cape Town, Cape Town, South Africa, 2016

[12] Tureyen A.K., Frosch R.J., Shear Tests of FRP-Reinforced Concrete Beams without Stirrups, ACI Structural Journal, 2002, 99(4): pp. 427-434

[13] El-Sayed A.K., El-Salakawy E.F. i Benmokrane B.,Shear Capacity of High-Strength Concrete Beams Reinforced with FRP Bars, ACI Structural Journal, 2006, 103(3): pp. 383-389

[14] Mari A.R., Cladera A., Oller E., Bairán J.,Shear design of FRP reinforced concrete beams without transverse reinforcement, Composites Part B: Engineering, 2014, 57: pp. 228-241

[15] Yang Y., Shear behaviour of reinforced concrete members without shear reinforcement, a new look at an old problem. PhD thesis, 2014, Delft University of Technology

[16] Muttoni A, Fernández Ruiz M. Shear strength of members without transverse reinforcement as function of critical shear crack width. ACI Structural Journal, 2008, 105(2): pp.163-72

[17] Alkhrdaji T., Wideman A., Belarbi A., Nanni A., Shear Strength of GFRP RC Beams and Slabs, Proceedings of the International Conference on Composites in Construction, Porto, Portugal, 2001

[18] El-Sayed A.K., El-Salakawy E.F., Benmokrane B., Shear strength of fibre-reinforced polymer reinforced concrete deep beams without web reinforcement, Canadian Journal of Civil Engineering, 2012, 39 (5): pp.546-555

[19] Matta F., El-Sayed A.K., Nanni A., Benmokrane B., Size Effect on Concrete Shear Strength in Beams reinforced with Fiber-reinforced polymer bars, ACI Structural Journal, 2013, 110 (4): pp. 617-628

[20] El-Sayed A.K., El-Salakawy E.F., Benmokrane B., Shear capacity of high-strength concrete beams reinforced with FRP bars, ACI Structural Journal, 2006, 103(3): pp. 383-389

[21] Leonhardt F. Shear and torsion in prestressed concrete. VI FIP Congr. Prague, vol. Session IV, 1970.

[22] Kani MW, Huggins MW, Wittkopp RR. Kani on shear in reinforced concrete. Dept. of Civil Engineering, University of Toronto, 1979.

[23] Cladera, A., Marí, A., Ribas, C., Bairán, J. and Oller, E.: Predicting the shear-flexural strength of slender reinforced concrete T and I shaped beams. Eng Struct, 2015, 101: pp. 386-398.

[24] Baghi, H., Shear strengthening of reinforced concrete beams with SHCC-FRP panels. 2015, University of Minho.

[25] ACI Committee, A.C.I., \& International Organization for Standardization, Building code requirements for structural concrete (ACI 318-08) and commentary. 2011, American Concrete Institute. 
[26] Bentz, E.C., Vecchio, F.J., Collins, M.P., Simplified Modified Compression Field Theory for Calculating Shear Strength of Reinforced Concrete Elements. ACI Structural Journal, 2006, 103: 614-624. [27] Kim JK, Park YD, Prediction of shear strength of reinforced concrete beams without web reinforcement. ACI Mater J, 1996, 93(3): pp.213-222.

[28] Imam M., Vandewalle L., Mortelmans F., and Van GD., Shear domain of fiber-reinforced high-strength concrete beam. J Eng struct, 1997, 19(9): pp.738-747.

[29] http://www.gom.com/3d-software/gom-correlate.html

[30] EN 206-1:2000 Concrete - Part 1: Specification, performance, production and conformity

[31] ISO 10406-1:2015(E). Fibre-reinforced polymer (FRP) reinforcement of concrete. Test methods - Part 1: FRP bars and grids

[32] Maekawa K., Pimanmas A., Okamura H., Nonlinear mechanics of reinforced concrete, Londyn, 2003

[33] Cavagnis F., Fernández Ruiz M., Muttoni A., Shear failures in rein-forced concrete members without transverse reinforcement: An analysis of the critical shear crack development on the basis of test results, Engineering Structures, 2015, 103: pp. 157-173

[34] Qureshi, J., Modeling of stress transfer across reinforced concrete interfaces, PhD thesis, University of Tokyo, Japan, 1993.

[35] Perry, C.C., "Data-Reduction Algorithms for Strain Gage Rosette Measurements", Experimental Techniques, 1989, pp. 13-18.

[36] Model Code 2010, vols. 1 \& 2, final draft, fib - Bulletins 65 \& 66, fib, Lausanne, 2012

[37] Baghi, H., Barros, A.O. Joaquim, New Approach to Predict Shear Capacity of Reinforced Concrete Beams Strengthened with Near-Surface-Mounted Technique, ACI Structural Journal, 2017, 114(1): pp. 137148.

[38] Gilman, J.R., Brickey, R.T., and Red, M.M., Monte Carlo Techniques for Evaluating Producing Properties. Society of Petroleum Engineers, 1998, https://doi.org/10.2118/39926-MS.

[39] Baghi, H., Barros, A.O. Joaquim, Design Approach to Determine Shear Capacity of Reinforced Concrete Beams Shear Strengthened with NSM Systems, Journal of Structural Engineering, 2017, 10.1061/(ASCE)ST.1943-541X.0001793.

[40] Moraes Neto, B., Barros, J., Melo, G., Model to Simulate the Contribution of Fiber Reinforcement for the Punching Resistance of RC Slabs, Journal of Materials in Civil Engineering, 2014, 26(7)

[41] Collins, M.P., Evaluation of shear design procedures for concrete structures, A.R.p.f.t.C.t.c.o.r.c. design, Editor, 2001. 


\section{Tables:}

Table 1. Details of test specimens

Table 2. Concrete composition

Table 3. The mechanical properties of experimentally tested GFRP bars.

Table 4. The main test results

\section{Tables:}

Table 1. Details of test specimens

\begin{tabular}{|c|c|c|c|c|c|c|c|c|}
\hline No. & Beams & $\begin{array}{c}\text { Type of } \\
\text { reinforcement }\end{array}$ & $\begin{array}{c}\text { Number of } \\
\text { layers }\end{array}$ & $\begin{array}{c}A \\
{\left[\mathrm{~mm}^{2}\right]}\end{array}$ & $\begin{array}{c}\Sigma L \\
{[\mathrm{~mm}]}\end{array}$ & $\begin{array}{c}\rho_{l} \\
{[\%]}\end{array}$ & $\begin{array}{c}\rho_{l} E_{l} \\
{[G P a]}\end{array}$ & $\begin{array}{c}d_{e q} \\
{[\mathrm{~mm}]}\end{array}$ \\
\hline 1 & G-512-30-15 & \multirow{7}{*}{ GFRP } & \multirow{5}{*}{1} & 565 & 188 & 0.99 & 0.51 & 379 \\
\hline 2 & G-316-30-15 & & & 603 & 151 & 1.07 & 0.55 & 377 \\
\hline 3 & G-318-30-15 & & & 763 & 170 & 1.35 & 0.70 & 376 \\
\hline 4 & G-416-30-15 & & & 804 & 201 & 1.42 & 0.73 & 377 \\
\hline 5 & G-418-30-15 & & & 1018 & 226 & 1.80 & 0.93 & 376 \\
\hline 6 & G-312/212-30-15 & & \multirow{2}{*}{2} & 565 & 188 & 1.02 & 0.53 & 368 \\
\hline 7 & G-318/118- 30-15 & & & 1018 & 226 & 1.85 & 0.95 & 367 \\
\hline \multicolumn{9}{|c|}{$\begin{array}{l}\rho_{l}=A / b_{w} d_{e q}: A \text { - cross sectional area of the reinforcement, } d_{e q}-\text { equivalent depth of the reinforcement } \\
d_{e q}=\left(A_{1} \times d_{1}+A_{2} \times d_{2}\right) / A: d_{1}, d_{2}-\text { depth of first and second reinforcement layer, } A_{1}, A_{2}-\text { the cross sectional area } \\
\text { of first and second reinforcement layer, } \Sigma L \text { - total perimeter of the reinforcement }\end{array}$} \\
\hline
\end{tabular}


Table 2. Concrete composition

\begin{tabular}{|l|c|c|}
\hline Components & $\begin{array}{c}\text { Quantity } \\
{\left[\mathrm{kg} / \mathrm{m}^{3}\right]}\end{array}$ & $\begin{array}{c}\text { Ratio } \\
{[\%]}\end{array}$ \\
\hline sand 0/2 & 970 & 42.33 \\
\hline crushed stone $2 / 8$ & 860 & 37.53 \\
\hline water & 205 & 8.94 \\
\hline CEM I 42.5 Rudniki CEMEX & 255 & 11.13 \\
\hline plasticizer BV-Cemex Admixtures & 1.8 & 0.07 \\
\hline Total & $\sum=2291.8$ & 100.00 \\
\hline
\end{tabular}


Table 3. The mechanical properties of experimentally tested GFRP bars.

\begin{tabular}{cccc}
\hline $\begin{array}{c}\text { Type of } \\
\text { bars }\end{array}$ & $\begin{array}{c}\text { Nominal bar diameter } \\
{[\mathrm{mm}]}\end{array}$ & $\begin{array}{c}f_{f u} \\
{[\mathrm{MPa}]}\end{array}$ & $\begin{array}{c}E_{l} \\
{[\mathrm{GPa}]}\end{array}$ \\
\hline \multirow{2}{*}{ GFRP } & 12 & $1195(6 ; 4.7 \%)$ & $50.2(5 ; 0.4 \%)$ \\
& 16 & $1089(3 ; 1.4 \%)$ & $50.5(3 ; 0.4 \%)$ \\
& 18 & $987(6 ; 9.8 \%)$ & $50.9(5 ; 2.4 \%)$ \\
\hline
\end{tabular}


Table 4. The main test results

\begin{tabular}{ccccccccc}
\hline Beams & $\begin{array}{c}f_{c m} \\
{[M P a]}\end{array}$ & $\begin{array}{c}f_{c t, s p} \\
{[M P a]}\end{array}$ & $\begin{array}{c}\rho_{l} \\
{[\%]}\end{array}$ & $\begin{array}{c}d_{e q} \\
{[\mathrm{~mm}]}\end{array}$ & $\begin{array}{c}V_{\max } \\
{[\mathrm{kN}]}\end{array}$ & $\begin{array}{c}\tau_{\max } \\
{[M P a]}\end{array}$ & $\begin{array}{c}\theta \\
{[\circ]}\end{array}$ & $\begin{array}{c}\delta_{\text {Fmax }} \\
{[\mathrm{mm}]}\end{array}$ \\
\hline G-512-30-15 & 30.2 & 2.75 & 0.99 & 379 & 34.3 & 0.60 & 35 & 5.2 \\
G-316-30-15 & 28.8 & 2.95 & 1.07 & 377 & 31.7 & 0.56 & 25 & 3.4 \\
G-318-30-15 & 28.8 & 2.95 & 1.35 & 376 & 38.6 & 0.68 & 45 & 2.9 \\
G-416-30-15 & 30.5 & 2.70 & 1.42 & 377 & 34.8 & 0.61 & 41 & 2.7 \\
G-418-30-15 & 28.8 & 2.95 & 1.80 & 376 & 38.2 & 0.68 & 51 & 3.0 \\
G-312/212-30-15 & 31.7 & 3.05 & 1.02 & 368 & 34.8 & 0.63 & 27 & 3.7 \\
G-318/118-30-15 & 31.7 & 3.05 & 1.85 & 367 & 47.7 & 0.87 & 47 & 3.5 \\
\hline
\end{tabular}


Figures:

Figure 1. Reinforcement of tested beams (dimensions in $\mathrm{mm}$ )

Figure 2. Test set up: static scheme and LVDT gauges and rosette's direction (dimensions in mm)
a) G-512-30-15
b) G-316-30-15
c) G-312/212-30-15
d) $\mathrm{G}-318-30-15$
e) G-416-30-15
f) $\mathrm{G}-418-30-15$
g) G-318/118- 30-15

Figure 3. Cracking pattern development registered by DIC system (on the surface limited by blue dashed line) with location of the registered cracks (type A-G) for three chosen load levels and the final crack pattern after beams failure along the full shear region.

Figure 4 Shear stress vs. average mid-span deflection

Figure 5. Shear stress vs. principal concrete strain $\varepsilon_{1}, \varepsilon_{2}$

Figure 6. Comparison of the ultimate and cracking shear stress

Figure 7. Response of ultimate shear stress vs. reinforcement ratio

Figure 8. Response of the shear crack inclination vs. reinforcement ratio

\section{Figures:}




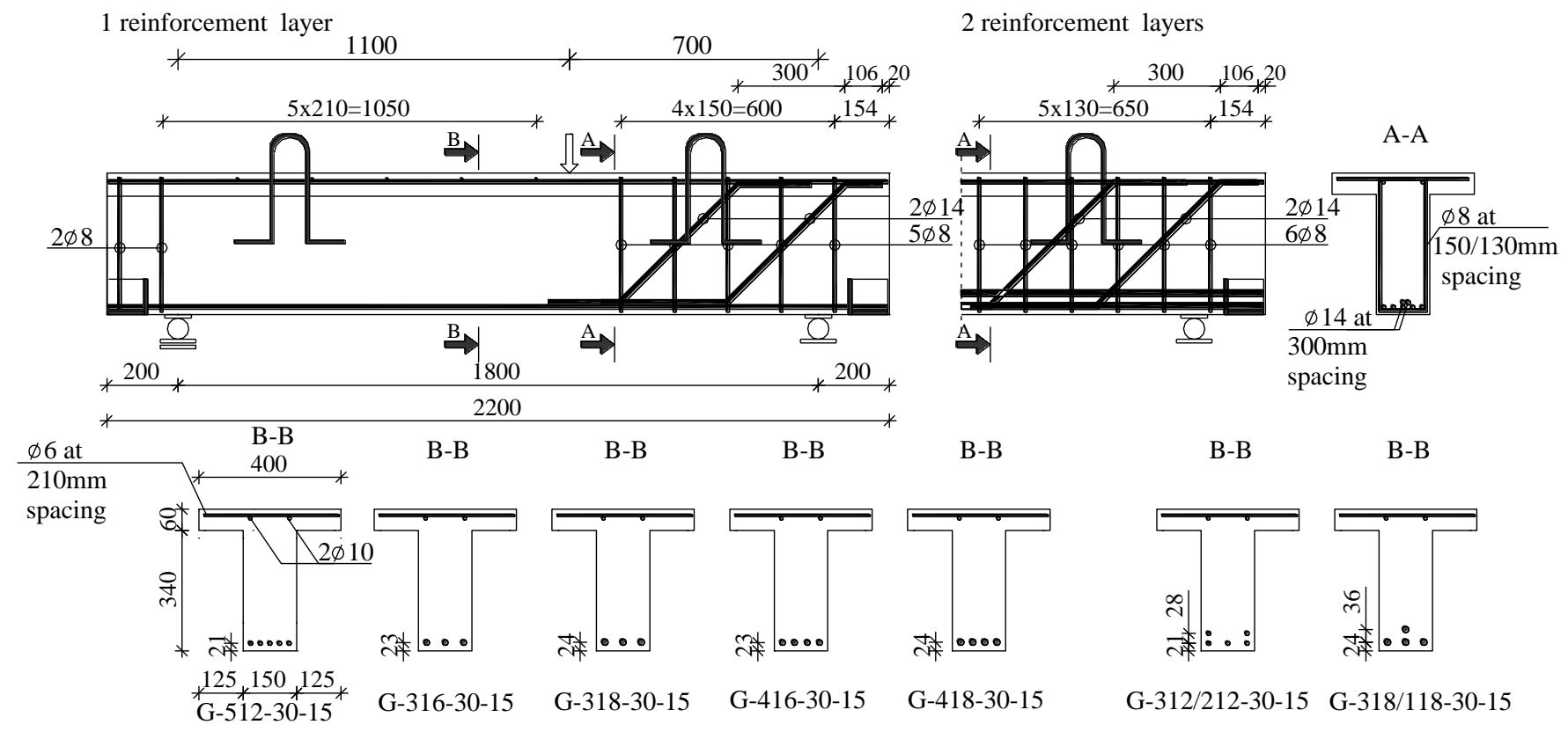

Figure 1. Reinforcement of tested beams (dimensions in $\mathrm{mm}$ ) 


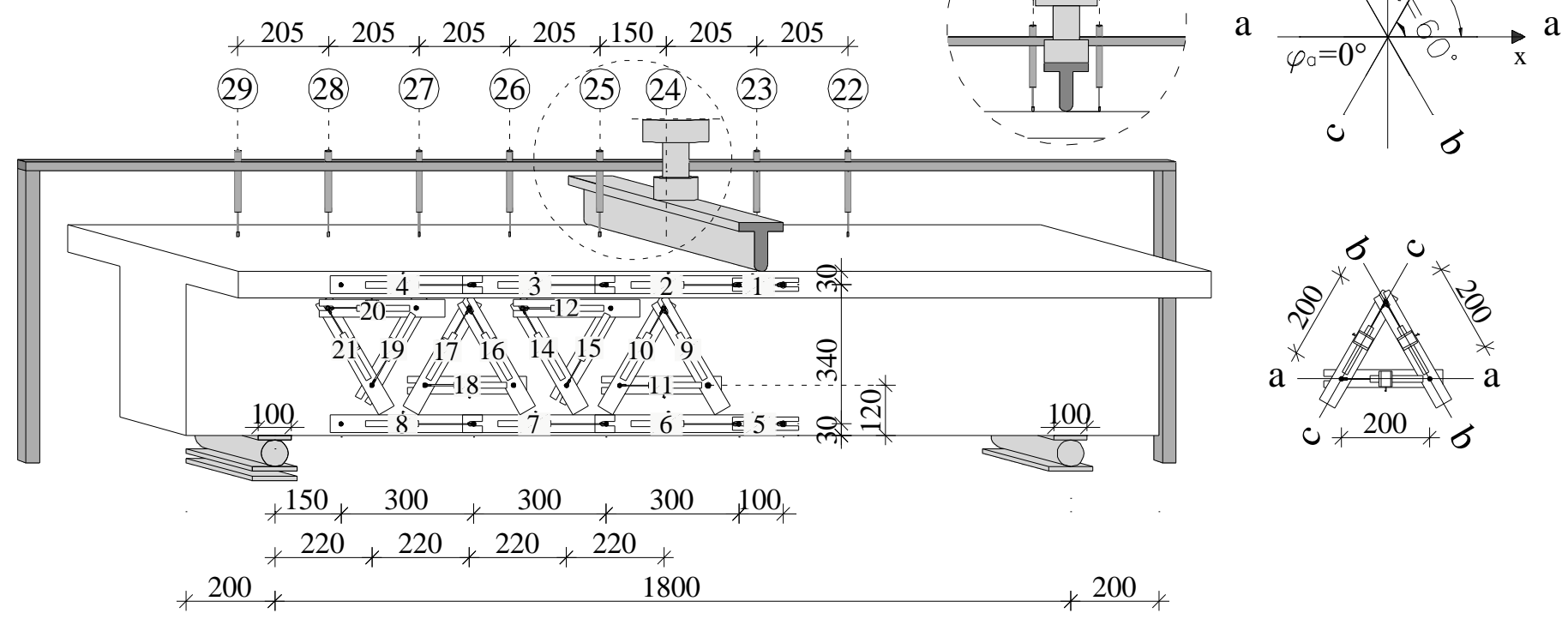

Figure 2. Test set up: static scheme and LVDT gauges and rosette's direction (dimensions in $\mathrm{mm}$ ) 
h) G-512-30-15
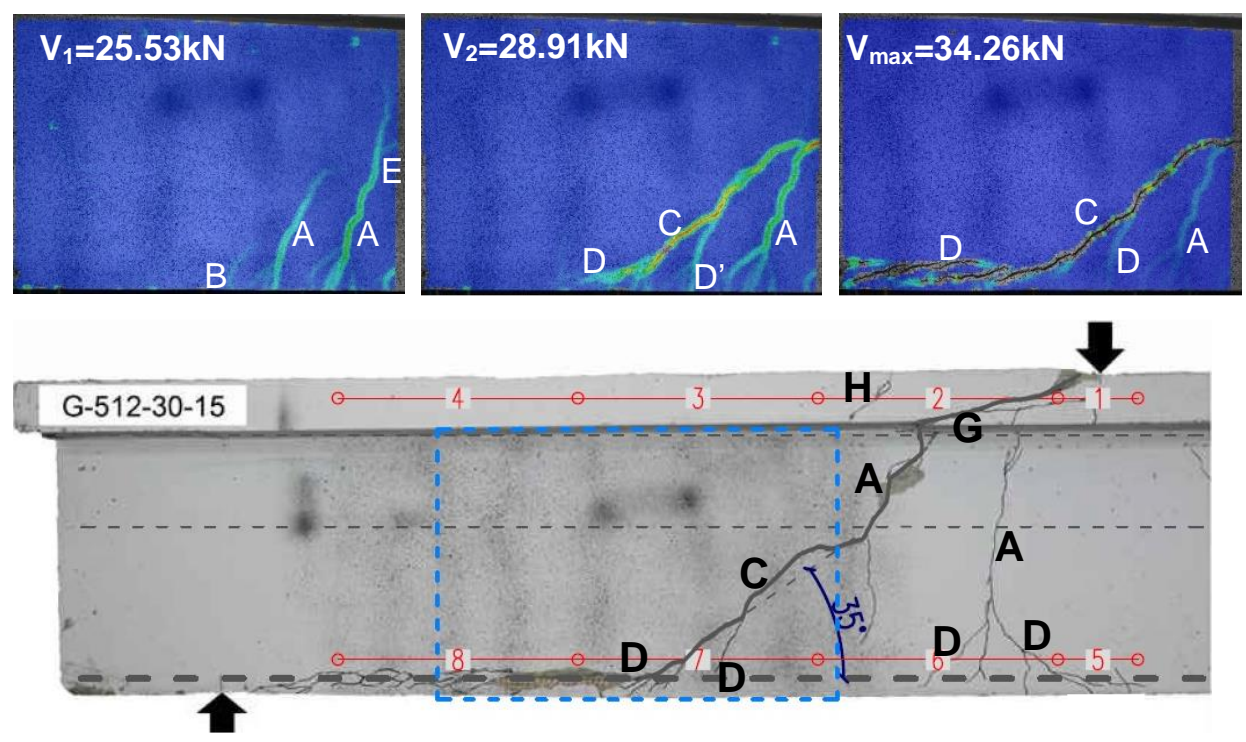

i) G-316-30-15

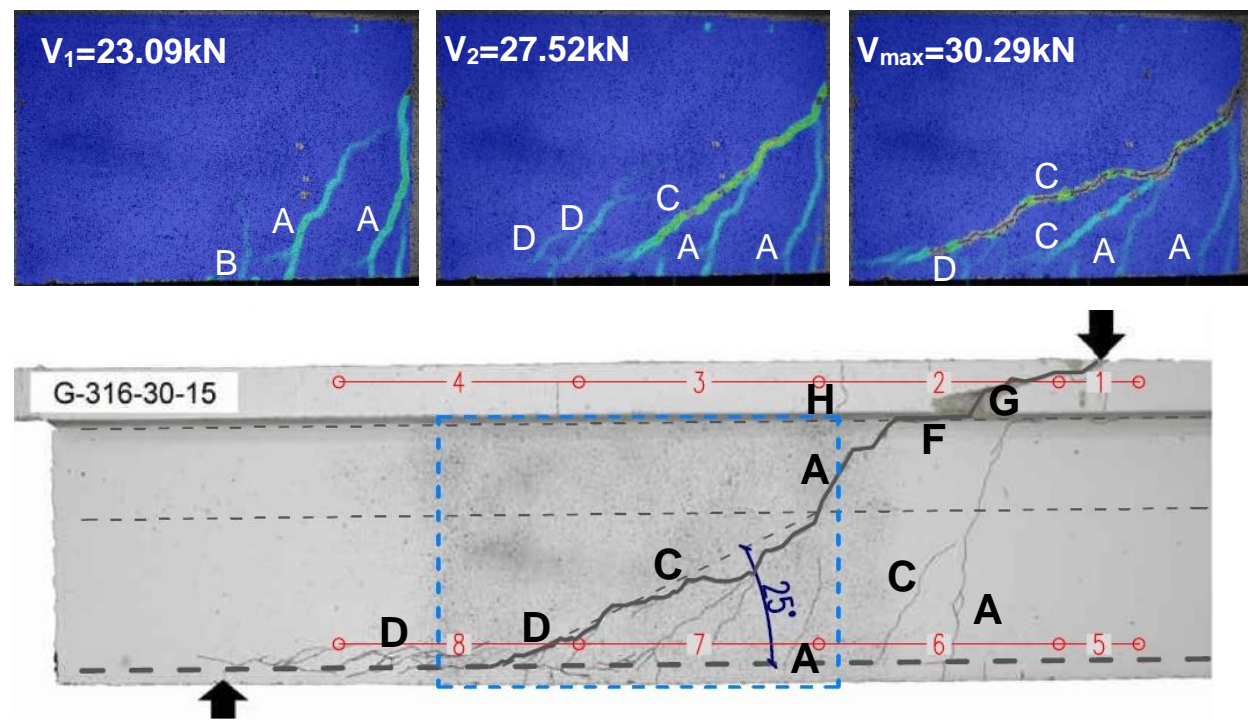

j) G-312/212-30-15
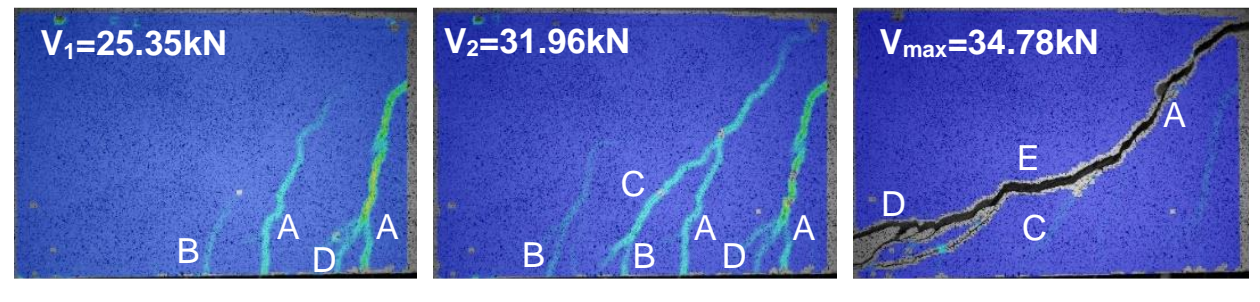


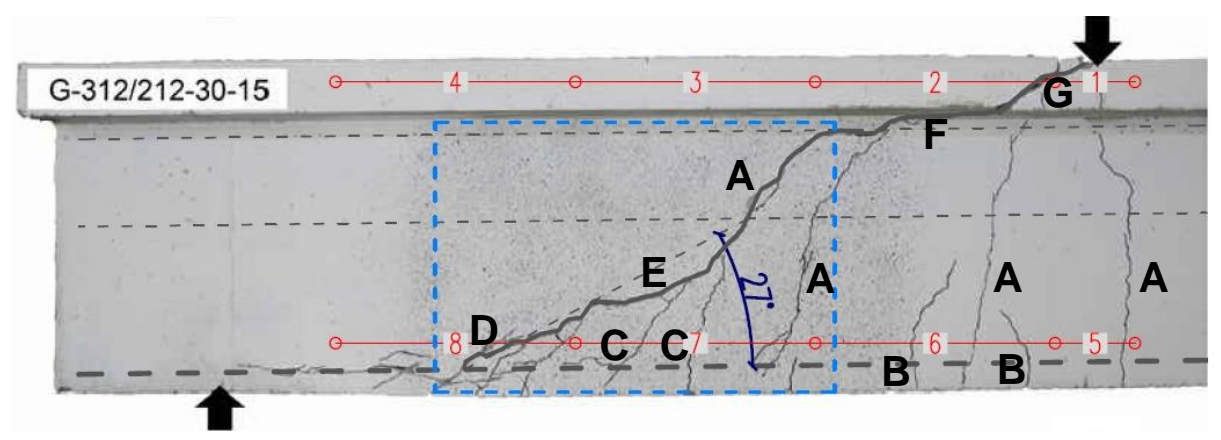

k) G-318-30-15
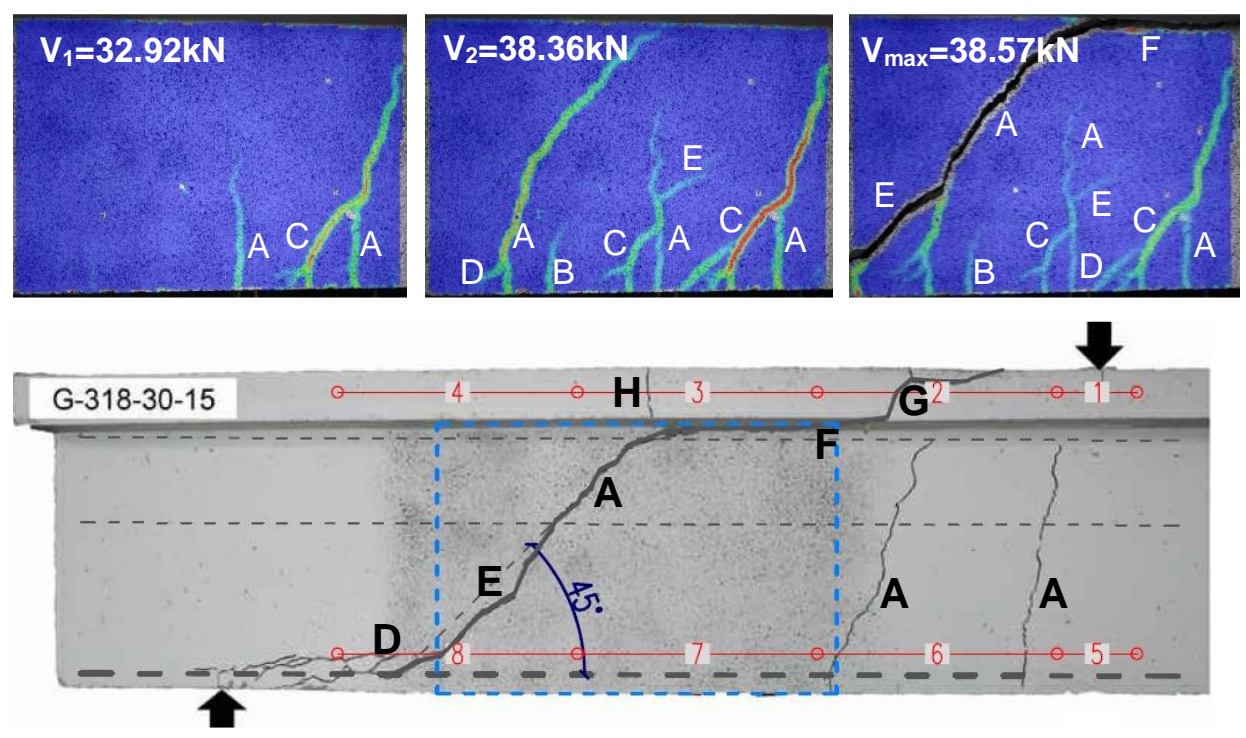

1) $\mathrm{G}-416-30-15$

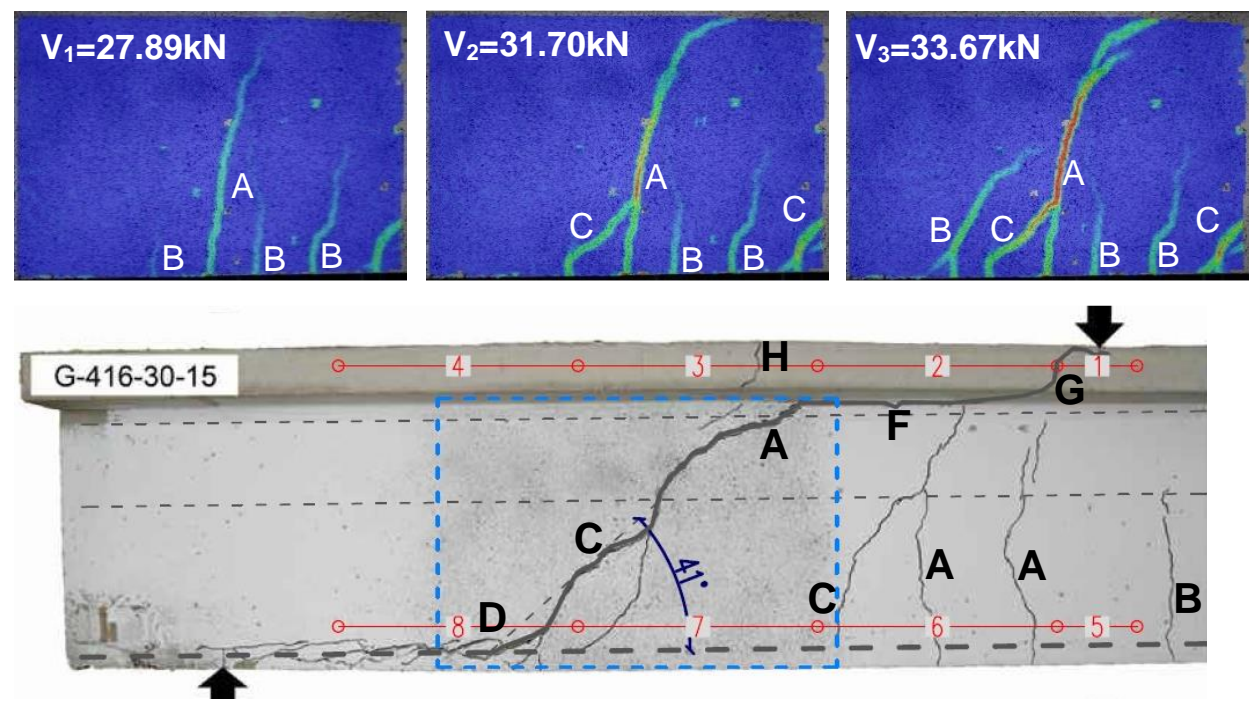

m) G-418-30-15 


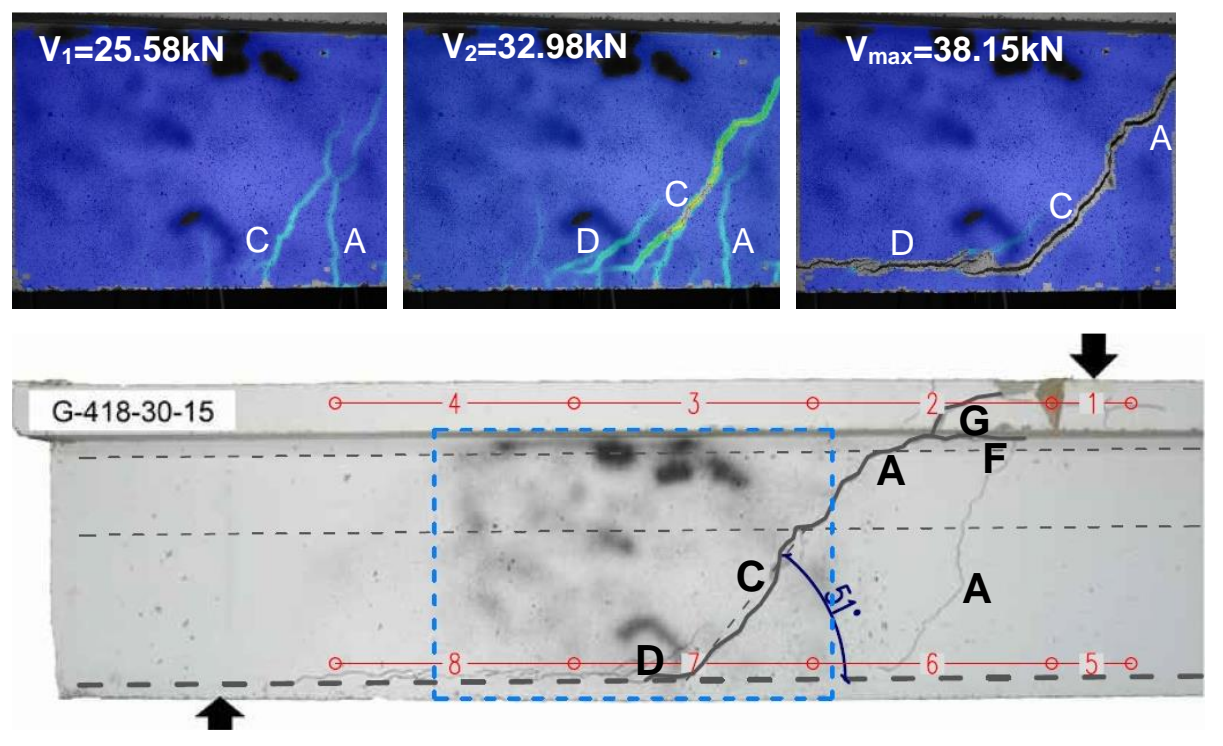

n) G-318/118- 30-15

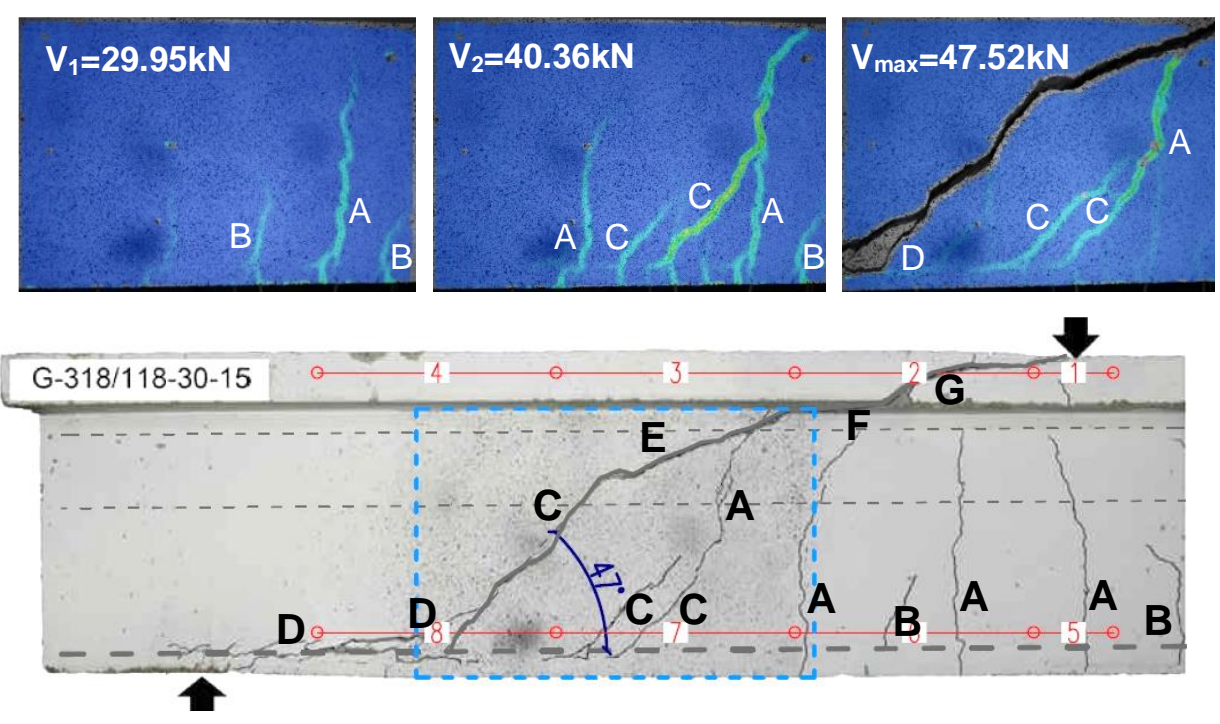

Figure 3. Cracking pattern development registered by DIC system (on the surface limited by blue dashed line) with location of the registered cracks (type A-H) for three chosen load levels and the final crack pattern after beams failure along the full shear region. 


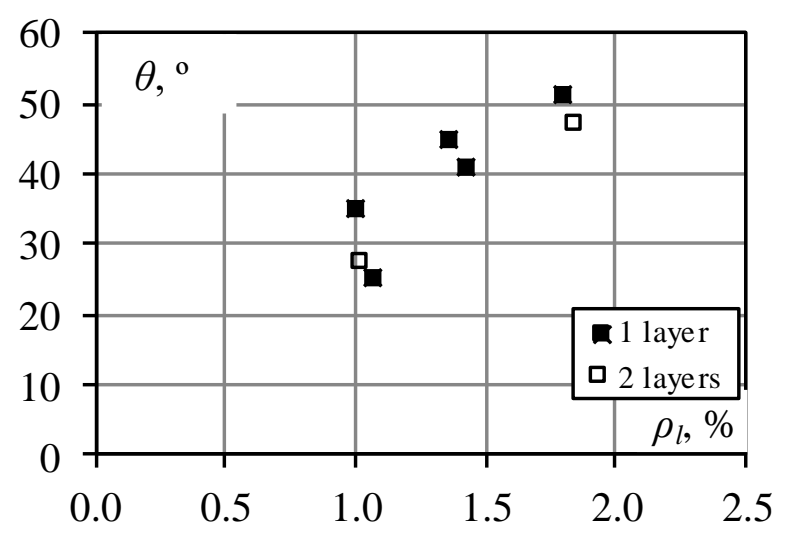

Figure 4. Response of the shear crack inclination vs. reinforcement ratio

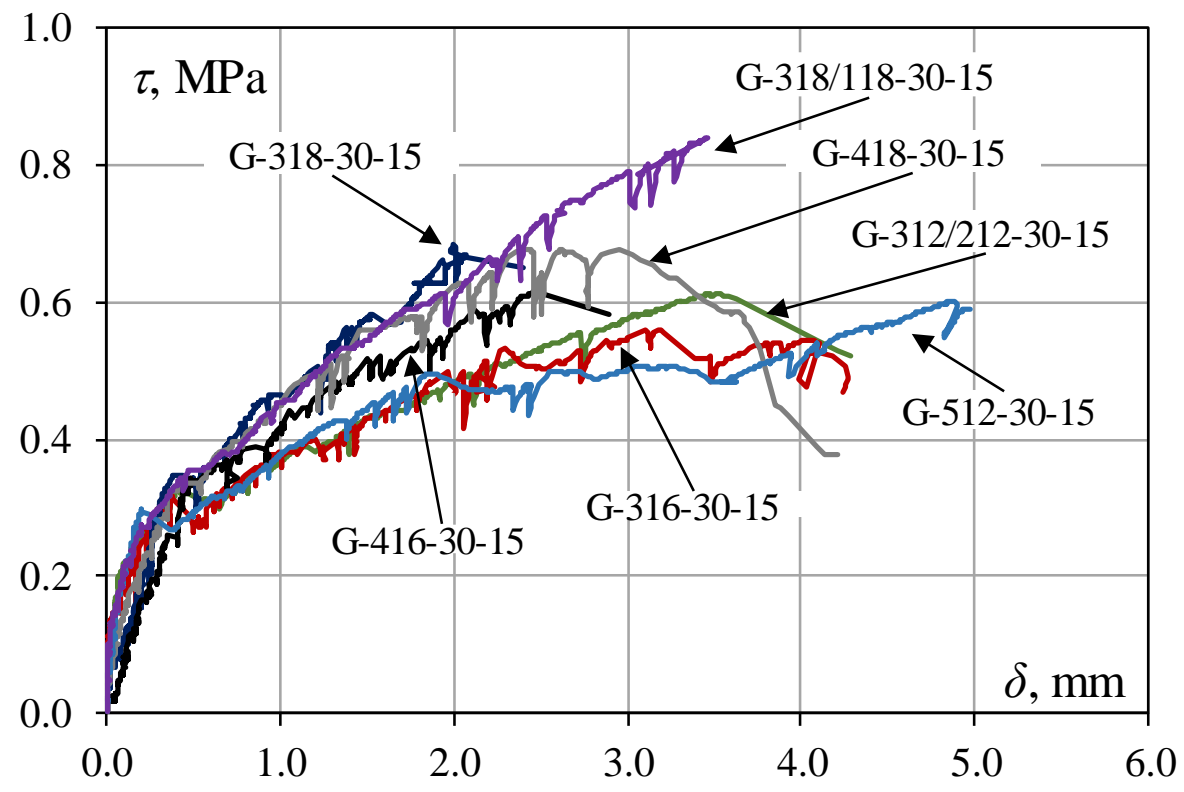

Figure 5. Shear stress vs. average mid-span deflection 


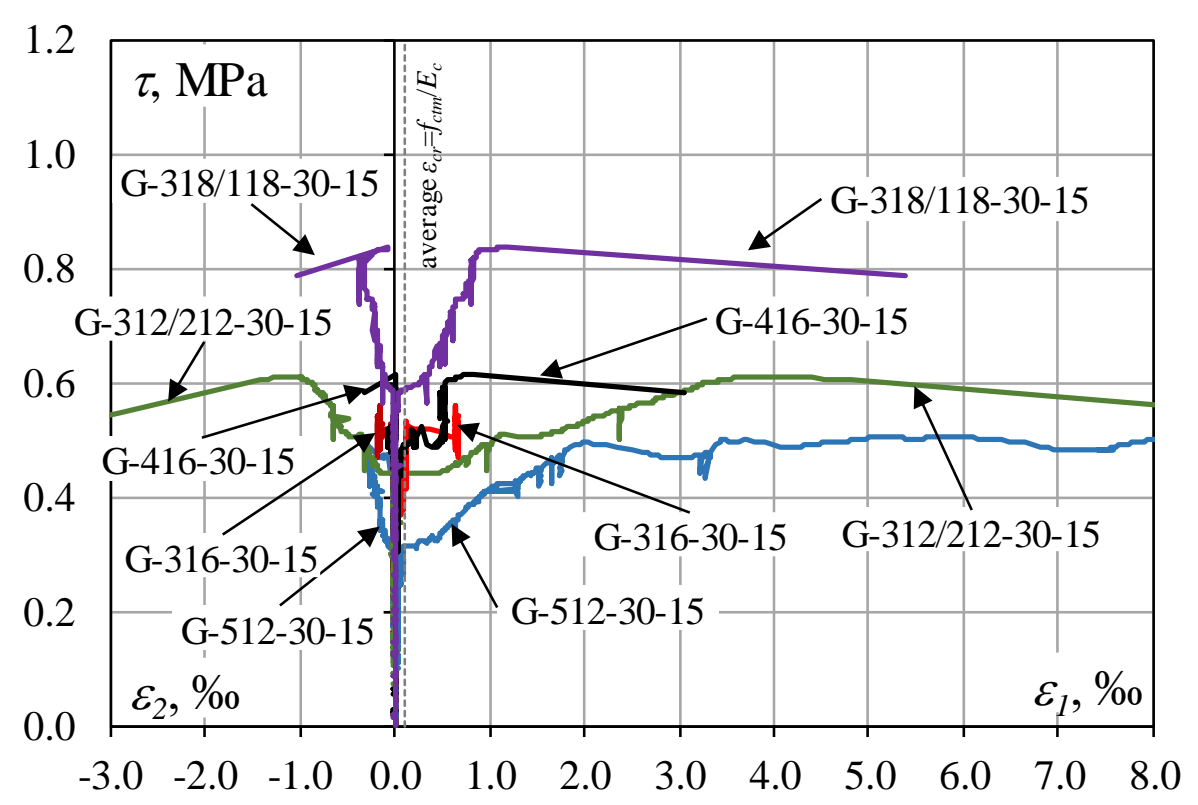

Figure 6. Shear stress vs. principal concrete strain $\varepsilon_{1}, \varepsilon_{2}$ 


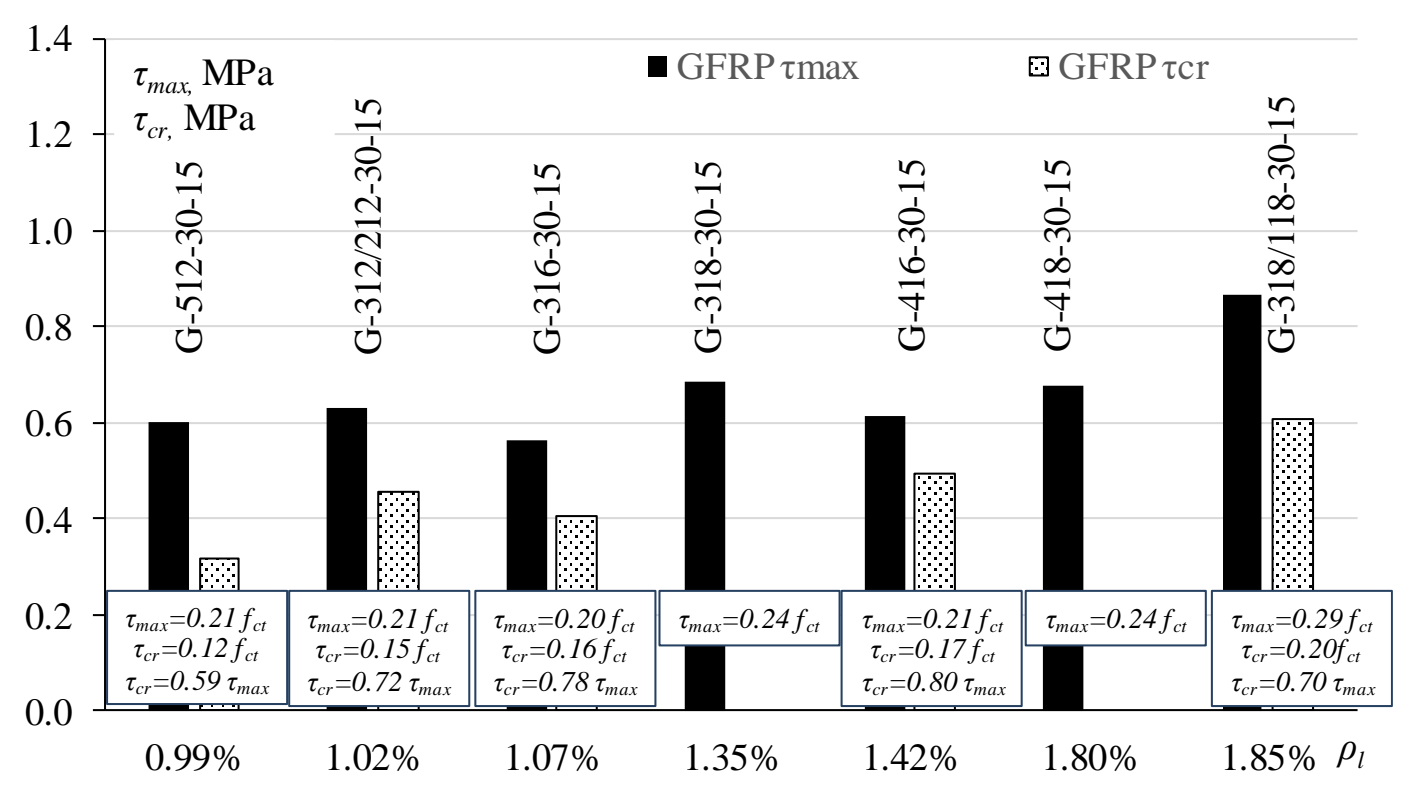

Figure 7. Comparison of the ultimate and cracking shear stress 


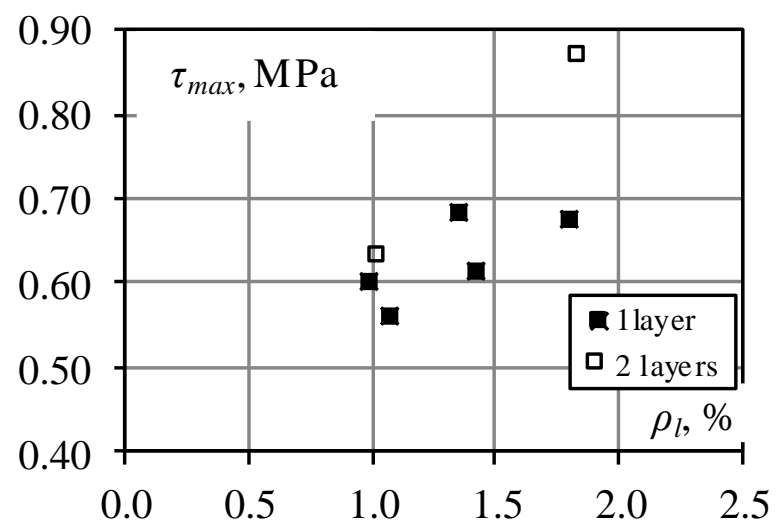

Figure 8. Response of ultimate shear stress vs. reinforcement ratio 